\title{
PRELIMINARY ASSESSMENT OF THE CHANGE IN THE MECHANICAL BEHAVIOR OF SYNTHETIC YARNS SUBMITTED TO CONSECUTIVE STIFFNESS TESTS
}

\author{
Felipe Tempel StumpF*, Carlos Eduardo marcos Guilherme, \\ Fulvio Enrico Giacomo Chimisso
}

\author{
POLICAB - Stress Analysis Laboratory, Av. Itália km.8, Rio Grande, Brazil \\ * corresponding author: felipe.stumpf@furg.br
}

\begin{abstract}
Anchoring systems of offshore platforms are designed to work uninterruptedly for 20 to 30 years, and despite the increasing number of studies concerning these systems' mechanical behavior in working conditions, most of them are conducted in speeding environments, due to the necessity of results in the short term. There are standardized stiffness tests, such as ISO 18692, based on quantities like Dynamic Stiffness and Quasi-static Stiffness, through which one can compare, quantitatively, two different ropes. However, there is a lack of research aiming to assess the change in the mechanical behavior of these ropes after certain number of consecutive loading cycles (or stiffness tests). This study aims to assess, at the yarn level, the change in the quasi-static and dynamic stiffness parameters of two materials when submitted to repeated stiffness tests. Results in terms of qualitative assessment of the mechanical behavior, as well as quantitative changes in the parameters are presented.
\end{abstract}

KEYwORDS: synthetic mooring ropes, ultra-deepwater, experimental mechanics.

\section{INTRODUCTION}

Mooring lines used as anchoring systems of oil platforms must be designed to work uninterruptedly over more than 20 years, which means that, from a mechanical design point of view, their material's mechanical behaviour must be well known (or, at least, accurately predictable) at each moment over the system's life span. In the case of steel wire cables, for quite a long time that was not a major concern of engineers, since the mechanical behaviour of such metallic materials tends not to suffer considering changes in that amount of time.

However, over the course of the last couple of decades, new oil fields have been discovered in ultradeepwater (5000 $\mathrm{m}$ to $7000 \mathrm{~m}$ water depth), what has led the oil companies to use light-weight materials as mooring lines of their platforms' anchoring system 11. Initially, polyester (PET) was considered the most suitable material for such applications [1], especially due to its low cost and its reliability in terms of small changes in the mechanical behaviour over time (very low creep rate, for instance). One of the main disadvantages of PET, however, is that it tends to show considerable elongation (aprox. $20 \%$ in rupture) in tension, what might present a problem for long mooring lines in terms of station-keeping [1, 2].

Aiming to find a more suitable option for these systems, the oil companies are testing several other synthetic materials, such as aramid, polyamide, high modulus polyethylene (HMPE), liquid crystal polyethylene, etc. All of those show a considerable lower elongation in comparison to PET 3, 4, but sometimes the price to be paid is a significant increase of their creep rate, or even higher production costs [5, 6]. High modulus polyethylene, for example, has the advantage to have a lower-than-water density [2, which means that it does not add weight to the platform when installed.

There are some standardized stiffness tests, such as ISO 18692:2013 [7, based on quantities such as Static Stiffness, Dynamic Stiffness (DS) and Quasistatic Stiffness (QSS), through which one can compare, quantitatively, the mechanical behavior of two different ropes after some pre-defined tension/creep loads. However, there is a lack of research aiming to assess the change in the mechanical behavior of these materials after a certain number of consecutive loading cycles (or stiffness tests). The present study aims to promote a preliminary assessment, at the yarn level, of the change in the quasi-static and dynamic stiffness parameters of these materials when submitted to repeated stiffness tests. Yarns of two different HMPE were submitted to a series of four consecutive stiffness experiments, with a period of ten hours between tests to promote possible relaxation of the samples in controlled environment.

\section{Quasi-Static Stiffness And DyNAMiC STIFFnEsS}

The industry, both oil companies and rope makers, make use of [7] to measure QSS and DS of their products in order to compare the stiffness of different materials or different rope configurations.

\subsection{Quasi-Static Stiffness}

According to the standard, the QSS consists in "the static stiffness, which is reduced to account for the 


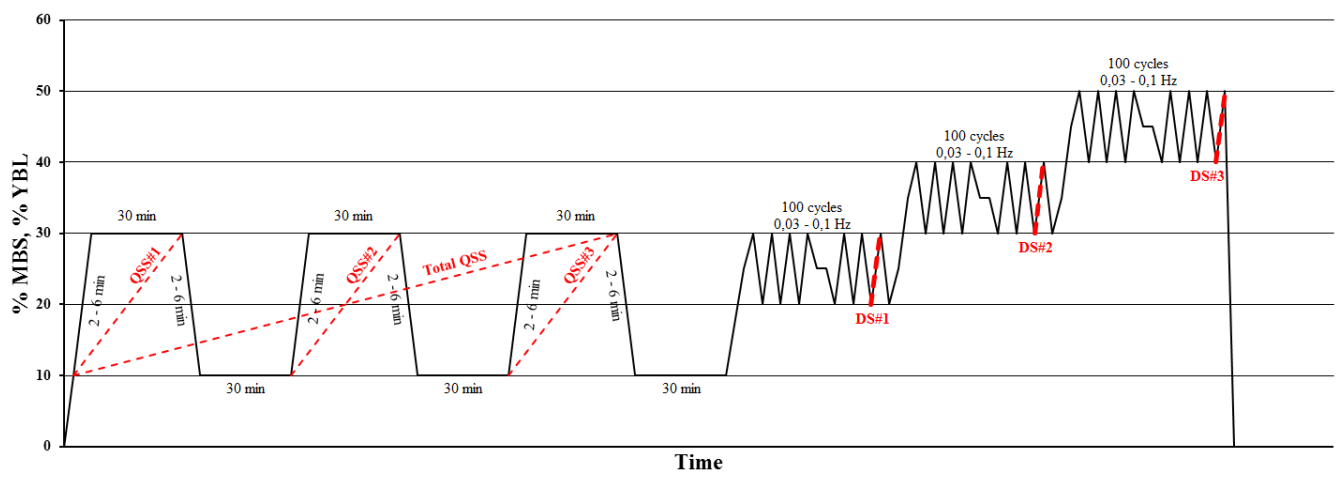

Figure 1. Test routine according to ISO 18692:2013 [7].

rope creep under an environmental event". During its life in service, a mooring rope is submitted not only to dynamic loadings, but also to constant loads at moderate to high intensity. Therefore, one must consider the creep behavior of these systems when designing an anchoring system, as well as the influence that this kind of loading has over the mechanical behavior of the rope. The quasi-static stiffness attempts to evaluate the loss in stiffness of the rope due to these creep regimes to which it is submitted during its lifetime.

\subsection{Dynamic Stiffness}

The definition of DS follows as "the ratio of change in load to change in strain in a rope under cyclic loading". It is a quite straighforward definition, since instead of the classic stiffness which is measured during quasistatic tension tests, it is obtained at the hundredth load cycle, as depicted in Figure 1 .

\section{Materials and Methods}

For a specific rope, subrope, strand, or yarn, the test routine depicted in Figure 1 together with Equation 1 are used to calculate QSS and DS.

$$
Q S S, D S=\frac{\frac{F_{Y}-F_{X}}{Y B L}}{\frac{L_{Y}-L_{X}}{L_{0}+L_{Y}}}
$$

The test routine (TR) showed in Figure 1 was performed four consecutive times (TR\#1, TR\#2, TR\#3 and TR\#4) for each sample and for each type of HMPE (HMPE\#1 and HMPE\#2), with an interval of 10 hours between experiments. At the end of each routine, the Quasi-static (QSS\#1, QSS\#2, QSS\#3, Total QSS) and the Dynamic Stiffness (DS\#1, DS\#2, DS\#3) were calculated.

The yarn samples were $500 \mathrm{~mm}$ long and were attached to the clamps of the machine using sandwich type endings. Figure 2 shows one of the samples. All the tests have been run at room temperature of $20 \pm$ $2{ }^{\circ} \mathrm{C}$ and $65 \pm 4 \%$ of air relative humidity.

The tests were performed on an Instron 8801 servohydraullic fatigue testing machine using a $10 \mathrm{kN}$ Dynacell load cell.

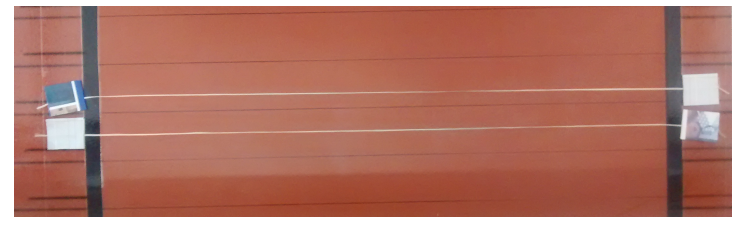

Figure 2. Typical yarns sample with sandwich type endings.

\section{Results}

Figures 36 and Tables 1,4 resume the results obtained for the evolution of QSS and DS of the two types of HMPE over each test routine.

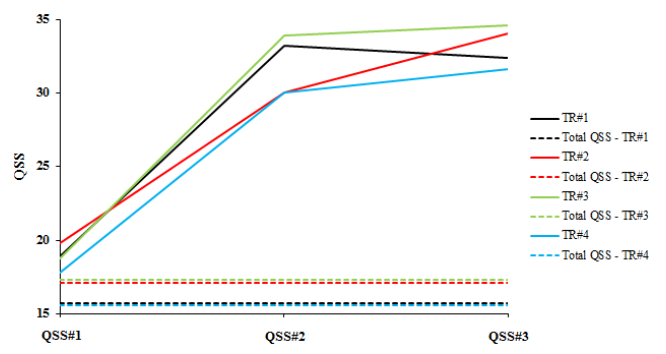

FIGURE 3. Evolution of QSS over each TR for HMPE\#1.

\begin{tabular}{lllll}
\hline & QSS\#1 & QSS\#2 & QSS\#3 & Total QSS \\
\hline TR\#1 & 18,9 & 33,2 & 32,4 & 15,7 \\
\hline TR\#2 & 19,8 & 30,1 & 34,0 & 17,1 \\
\hline TR\#3 & 18,7 & 33,9 & 34,6 & 17,3 \\
\hline TR\#4 & 17,8 & 30,0 & 31,7 & 15,6 \\
\hline
\end{tabular}

TABLE 1. Results for QSS: HMPE\#1.

\section{Conlcusions}

It can be seen that both quasi-static and dynamic stiffness of both materials show, in general, a stabilizing tendency along calculations \#1, \#2 and \#3. The first stiffness (QSS\#1 and DS\#1) is always the lowest one, followed by a considerable increase at moment \#2 (QSS\#2 and DS\#2) and, finally, a smaller increase 


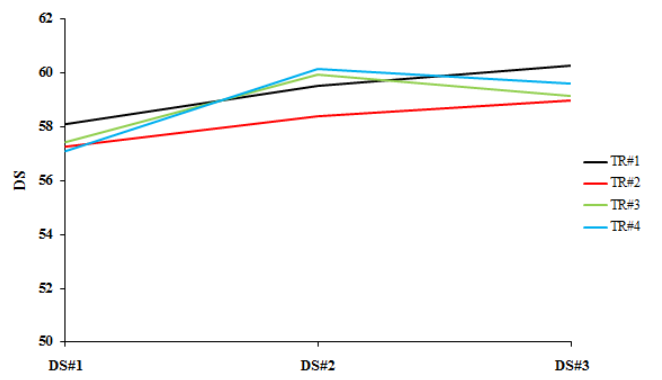

Figure 4. Evolution of DS over each TR for HMPE\#1.

\begin{tabular}{llll}
\hline & DS\#1 & DS\#2 & DS\#3 \\
\hline TR\#1 & 58,1 & 59,5 & 60,3 \\
\hline TR\#2 & 57,3 & 58,4 & 59,0 \\
\hline $\mathrm{TR \# 3}$ & 57,4 & 60,0 & 59,2 \\
\hline $\mathrm{TR \# 4}$ & 57,1 & 60,1 & 59,6 \\
\hline
\end{tabular}

TABLE 2. Results for DS: HMPE\#1.

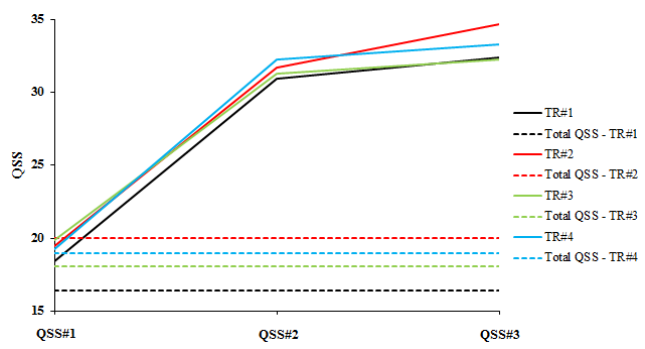

FIGURE 5. Evolution of QSS over each TR for HMPE\#2.

\begin{tabular}{lllll}
\hline & QSS\#1 & QSS\#2 & QSS\#3 & Total QSS \\
\hline TR\#1 & 18,4 & 30,9 & 32,4 & 16,4 \\
\hline $\mathrm{TR} \# 2$ & 19,4 & 31,7 & 34,7 & 20,0 \\
\hline $\mathrm{TR} \# 3$ & 19,9 & 31,3 & 32,2 & 18,1 \\
\hline $\mathrm{TR} \# 4$ & 19,2 & 32,2 & 33,3 & 19,0 \\
\hline
\end{tabular}

TABLE 3. Results for QSS: HMPE\#2.

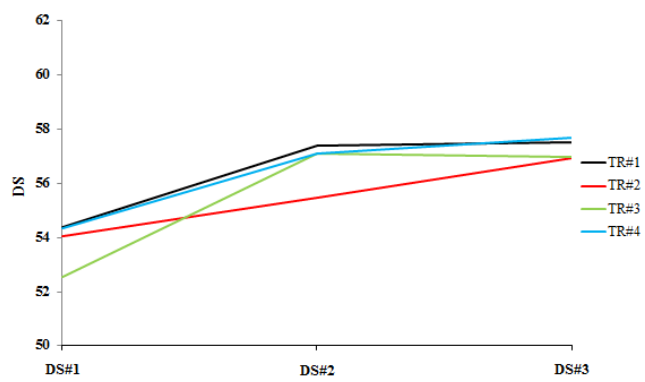

Figure 6. Evolution of DS over each TR for HMPE\#2.

up to calculation \#3 (QSS\#3 and DS\#3). In other words, the more you cycle these materials, the more stiff they get, until they reach what appears to be a limiting stiffness.

\begin{tabular}{llll}
\hline & DS\#1 & DS\#2 & DS\#3 \\
\hline TR\#1 & 54,4 & 57,4 & 57,5 \\
\hline TR\#2 & 54,0 & 55,5 & 56,9 \\
\hline TR\#3 & 52,6 & 57,1 & 57,0 \\
\hline TR\#4 & 54,3 & 57,1 & 57,7 \\
\hline
\end{tabular}

TABLE 4. Results for DS: HMPE\#2.

In terms of the quasi-static stiffness, the Total QSS (dashed lines in Figures 3 6) tends to be similar to QSS\#1, leading to the conclusion that both can be used for a conservative approach.

Comparing results between $\mathrm{TR} \# 1, \mathrm{TR} \# 2$, TR\#3 and $\mathrm{TR} \# 4$, there is no evidence, so far, that the consecutive loading of the same specimen leads to a trending change of these stiffness properties for HMPE. Perhaps, if the routines were repeated a few more times, we could see a drop in QSS and DS, what would mean that the material is becoming less stiff with time, what could be a problem in terms of designing a mooring line.

\section{LIST OF SYMBOLS}

$F$ Force $[\mathrm{N}]$

$Y B L$ Yarn Break Load [N]

$L \quad$ Elongation $[\mathrm{m}]$

\section{ACKNOWLEDGEMENTS}

POLICAB team would like to thank PETROBRAS Brazilian Petroleum - for sponsoring this work.

\section{REFERENCES}

[1] C. J. M. D. Vecchio. Light weight materials for deep water moorings. PhD Thesis. University of Reading, 1992.

[2] P. Davies, Y. Reaud, L. Dussud, P. Woerther. Mechanical behaviour of HMPE and aramid fibre ropes for deep sea handling operations. Ocean Engineering 38:2208-2214, 2011. DOI:10.1016/j.oceaneng.2011.10.010

[3] P. Davies, S. D. Weller, L. Johanning, S. J. Banfield. A review of synthetic fiber moorings for marine energy applications. 5th International Conference on Ocean Energy (ICOE 2014) 2014.

[4] S. Leite, J. Boesten. HMPE mooring lines for deepwater MODUs. Offshore Technology Conference (OTC) 2011.

[5] W. Huang, H. Liu, Y. Lian, L. Li. Modeling nonlinear creep and recovery behaviors of synthetic fiber ropes for deepwater moorings. Applied Ocean Research 39:113-120, 2012. DOI:10.1016/j.apor.2012.10.004

[6] H. S. d. C. Mattos, F. E. G. Chimisso. Modelling creep tests in HMPE fibres used in ultra-deep-sea mooring ropes. Int J Sol Struct 48:144-152, 2011. DOI:10.1016/j.ijsolstr.2010.09.015.

[7] International Organization for Standardization. ISO 18692:2013: Fibre ropes for offshore stationkeeping Polyester, 2013. 